Voix et Images

voixetimages

\title{
Jack Kerouac : une conscience de la mort
}

\section{Guy Perreault}

Volume 13, numéro 3 (39), printemps 1988

Jack Kerouac et l’imaginaire québécois

URI : https://id.erudit.org/iderudit/200728ar

DOI : https://doi.org/10.7202/200728ar

Aller au sommaire du numéro

Éditeur(s)

Université du Québec à Montréal

ISSN

0318-9201 (imprimé)

1705-933X (numérique)

Découvrir la revue

Citer cet article

Perreault, G. (1988). Jack Kerouac : une conscience de la mort. Voix et Images, 13(3), 402-407. https://doi.org/10.7202/200728ar d'utilisation que vous pouvez consulter en ligne.

https://apropos.erudit.org/fr/usagers/politique-dutilisation/ 


\title{
Jack Kerouac: une conscience de la mort
}

\author{
par Guy Perreault, Université du Québec à Montréal
}

J'ai un coup de cafard, il faut que je rentre. Chacun d'entre nous, né pour mourir. Jack Kerouac, Tristessa, p. 47.

Jack Kerouac a aimé la vie; il l'a parcourue, l'a décrite dans ses livres, n'ayant jamais peur de descendre en des profondeurs où n'accède qu'un petit nombre du commun des mortels. Aussi s'est-il parfois tourné du côté «sombre», du côté «terrible» des choses, semblable en ce sens au Rainer Maria Rilke des Cahiers de Malte Laurids Brigge, qui disait, par la bouche de son narrateur, qu'il faut se surmonter jusqu'à coucher à côté d'un lépreux, jusqu'à le réchauffer à la chaleur intime des nuits d'amour...1. Jack Kerouac avait lui aussi son lépreux, ou plutôt ses lépreux, ses chers clochards avec qui il trinquait certaines nuits chaudes, sur le bord des routes ou des voies ferrées, en Amérique.

Le rapprochement entre Rilke et Kerouac n'est pas fortuit. Bien qu'ils aient vécu à des époques différentes, bon nombre de traits les unissent. Rilke n'était-il pas lui aussi nomade, allant de château en château à travers l'Europe? Les deux écrivains, par leur écriture respective, se sont toujours attachés à parler de la vie, et aussi de la mort; Rilke, dans les Cahiers de Malte Laurids Brigge, et Kerouac, tout au long de son œuvre, brièvement dans ses romans «d'action» (Sur la route, les Clochards célestes), plus particulièrement dans les romans du cycle lowellien (Visions de Gérard, Docteur Sax: partie quatre, «La nuit où l'homme à la pastèque mourut») et dans Tristessa. Kerouac évoque encore Rilke par le regard qu'il porte sur la totalité des choses de ce monde: un regard «neutre» qui s'intéresse à la fois à la beauté et à la laideur. C'est le Rilke effrayé, découvrant ce Paris début de siècle, jusqu'à ce que Rodin lui apprenne à regarder. De la même façon, c'est grâce à Tom Wolfe que Kerouac apprend à «voir l'Amérique réelle, sans fard» 2 , aux ruelles sales et mal éclairées. C'est l'Amérique clinquante que chantera Kerouac, pas celle de la bourgeoisie.

L'obsession de la mort traverse toute l'œuvre de Kerouac, bien qu'elle marque plus intensément certains textes. C'est le cas de Tristessa et de Visons de Gérard qui seront ici étudiés.

1 Rainer Maria Rilke, les Cahiers de Malte Laurids Brigge, Paris, Seuil, coll. «Points», 1966, p. 69.

2 Jack Kerouac, Vanité de Duluoz, Paris, Christian Bourgois, 1979, p. 92. 


\title{
Visions de Gérard: apprentissage de la souffrance
}

\author{
Mon pauvre Ti-Loup, tu es né pour souffrir. \\ Visions de Gérard, p. 9.
}

Visions de Gérard se présente sous forme de fragments. Le narrateur y raconte, imagine parfois, les événements entourant les souffrances et la mort de son frère Gérard, à l'âge de neuf ans. Oraison funèbre, chant de mort où renaît par le souvenir tout le poids d'une immense douleur. C'est la souffrance de toute une famille qui tient place dans ces pages profondément marquées par une conscience de la douleur et de la mort. Et cette douleur qui revient à la surface n'est pas seulement celle du passé. Il s'agit bien d'une souffrance aiguẽ, réelle, qui a grandi avec le temps; d'une souffrance qui manquait au narrateur lorsqu'il vécut ces jours «tristes» (il n'avait que quatre ans), et qui maintenant ne lui fait plus défaut alors qu'il entreprend, par écrit, l'itinéraire des demiers jours de son frère. Cette entreprise est par ailleurs condamnée dès l'abord à une certaine forme d'impuissance:

Je voudrais pouvoir me rappeler la tendresse de ces deux frères solitaires qui se pelotonnaient l'un contre l'autre, dans un passé si éloigné de ma frêle entreprise à présent, que je ne pourrais rien tirer de ses vertus bienfaisantes, même si une passerelle me reliait à lui, car j'ai perdu toutes mes molécules d'alors et je n'ai plus en moi leur saveur révélatrice ${ }^{3}$.

C'est sans doute pour cela que le narrateur déploie son imaginaire jusqu'à inventer certains événements entourant la mort de Gérard, dont une partie de poker impliquant le père. Il se rappelle toutefois avec exactitude la veille de Noël, celle de mil neuf cent vingt-cinq, et la décrit avec force détails: Je me souviens encore de la qualité de ce ciel, ce même soir, et pourtant, je n'avais que trois ans 4 . Cette conscience qui se remémore la «qualité» d'un ciel, cette voix qui nous dévoile ses Visions de Gérard, avec son grain spécial, sa vertu mnésique puissante, c'est celle qui apprend la douleur, qui la réapprend, revivant les souffrances de toute une famille. Le narrateur ne nous convie pas seulement à une lecture où il nous fait partager ses souvenirs. Il revit, du moins le tente-t-il, les souffrances de son frère, parvenant à saisir le martyr que celui-ci dut endurer. Et probablement comprend-il toute l'horreur de l'être confronté à la douleur et à la mort: C'est la pensée humaine et constante tandis que la douleur continue de le torturer 5 ; Les mots sont impuissants ${ }^{6}$. Le narrateur ne se contente pas de revivre le martyr de Gérard; il inclut dans son discours les voix du père et de la mère qu'il porte en lui dans un même souffle. Il souffre ce qu'a souffert le père en perdant son préféré, il connaît le désespoir de la mère qui n'a pas souffert autant que son fils [...] et il est retourné à la terre. Gémit ma mère en comprenant quel désespoir

3 Jack Kerouac, Visions de Gérard, Paris, Gallimard, coll. «Du monde entier», 1972, p. 11.

4 Ibid., p. 93.

5 Ibid., p. 111-112.

6 Ibid., p. 111. 
total il y a dans la perte de la vie et dans la mort 7 . Parvenant à reproduire les différents sentiments que l'agonie et la mort de Gérard ont suscités, le narrateur ne retrouve-t-il pas toute la saveur révélatrice de ses molécules d'enfant de quatre ans, alors témoin d'une tragédie?

Cette voix, donc, qui se rappelle, conscience de la souffrance et conscience de la mort, est aussi conscience du processus de désintégration qu'est la vie. Les hommes substantiels ${ }^{8}$ sont appelés à disparaître comme les cheminées de Lowell. Cette mort qui menace Gérard, qui l'a usé pour finalement l'emporter, c'est la mort de tous les hommes: C'est la mort, l'inévitable mort, oh, pitié la souffrance de la mort 9 ; [...] vivre seulement pour mourir $10 ;$ Nous vivons pour mourir11. Mais le caractère inévitable de la mort suggère au narrateur un aspect positif de cet événement:

Bénissez mon âme, la mort est le seul sujet qui vaille la peine, car elle marque la fin de l'illusion et de l'erreur - La mort, c'est l'autre face de la même pièce de monnaie, que nous appelons maintenant la vie 12 .

Visions de Gérard, tout comme Tristessa, s'inscrit dans une sorte de combat, de lutte, que nous pourrions appeler «la lutte contre l'oubli». Notre univers est peuplé de créatures passagères, aléatoires, vouées à cette mort qui frappa Gérard. Mais il nous reste un texte qui le louange et qui nous parle, avec force, du petit «saint» qu'il fut pour un plus petit que lui.

\section{Tristessa: l'incarnation de la mort}

Nous sommes rien.

Demain nous pouvons mourir.

Nous sommes rien.

Toi et moi.

Tristessa, p. 86.

Tout comme Visions de Gérard, Tristessa se présente sous forme de fragments. Mais ici, une impression de «dérive» alcoolique se dégage du texte; ce qui n'est pas sans rappeler Au-dessous du volcan de Malcolm Lowry. Tout comme le narrateur qui se remémorait les souffrances de son frère, celui de Tristessa porte en lui une conscience de la douleur: Je suis triste parce que toute la vida es dolorosa 13 . Cette fois-ci, l'action se situe à Mexico. Nous ne sommes plus à Lowell ni sur la route, mais quelque part entre deux voyages. Il

$7 \quad$ Ibid., p. 180.

8. Ibid., p. 8.

9 Ibid., p. 108.

10 Ibid., p. 185.

11 Ibid., p. 77.

12 Ibid., p. 162-163.

13 Jack Kerouac, Tristessa, Montréal, Québec/Amérique, coll. «Littérature d'Amérique», 1983, p. 27. 
s'agit d'une halte où la conscience «remémorante» fait jaillir les moments d'une étrange histoire d'amour. Tristessa, bien entendu, est le nom de la femme aimée. Le narrateur s'en éloigne toujours, tournant sans cesse autour du sujet sans jamais l'atteindre. C'est qu'il est préoccupé par des individus obsédés par la drogue; Tristessa n'y échappe pas. Mais il y a plus. Obsédé par son désir pour Tristessa, dont il est follement amoureux, le narrateur poursuit un autre but, attaché à son développement spirituel celui-là, qui est de demeurer chaste et pur: J'ai renoncé d̀ désirer les femmes - pour sauver mon désir - renoncé au sexe et aux pulsions limitées - je veux me fondre dans le fleuve divin...14. Deux quêtes, donc, dont l'une risque toujours d'annihiler l'autre. N'avons-nous pas ici l'explication du titre de la première partie: «Tremblant et chaste»?

Incarnation de la mort, Gérard portait le masque blafard de l'agonie. Incarnation de la mort, Tristessa porte les stigmates des drogués en état de manque, dans un Mexique où domine la pauvreté. Mais cet attribut négatif est loin de l'enlaidir. Aux yeux du narrateur, Tristessa est une sainte ${ }^{15}$, elle est associée à Damema, Mère des Bouddhas 16 et à une madone17; sa beauté est grande. Mais il sait qu'elle est morphinomane et qu'elle aime la mort 18 .

À la famille de Lowell, s'est substitué un petit cercle de drogués comprenant, outre Tristessa, Cruz, sa sœur, et El Indio, eux aussi nés pour mourir. En attendant leur dernière heure, ils se «piquent», histoire de rendre la vie moins angoissante. Le narrateur, tout comme dans Visions de Gérard, est en position de retrait. Il ne participe pas aux orgies des morphinomanes, d'autant plus qu'il ne comprend pas ce qu'ils se disent. Malgré tout, on le retrouve souvent auprès de Tristessa, dont la déchéance le torture. À l'écart du groupe, il se tourne du côté de la «basse-cour»: une poule et un coq orgueilleux, un chihuahua et un petit chat chétif, un pigeon perché sur le rebord d'une cheminée; ménagerie qui évolue avec ses cris et ses mouvements dans la maison de Tristessa. Puisque le narrateur ne peut entrer en contact avec ses semblables, c'est avec ses amis les bêtes qu'il va engager la conversation, à eux qu'il prêtera sans doute un peu de ses propres sentiments. Ainsi, à propos du chihuahua: Il médite sur la mort et le nirvana, sur cet acharnement des mortels à marchander le temps jusqu'à la fin 19 . Quant au pigeon: [...] il attend la pureté parfaite de la mort 20 . Tous ces animaux forment ainsi sa nouvelle famille. Quand il ne réussit pas à s'incorporer à Tristessa et aux autres, c'est toujours à eux qu'il s'adresse. En plus d'être une conscience de la douleur et de la mort qui touchent tous les hommes, le narrateur est aussi une conscience de la mort des animaux. Il est hanté par le sort réservé à tout être vivant:

\begin{tabular}{ll}
\hline 14 & Ibid., p. 32. \\
15 & Ibid., p. 33 \\
16 & Ibid., p. 43. \\
17 & Ibid., p. 33. \\
18 & Ibid., p. 34. \\
19 & Ibid., p. 45. \\
20 & Ibid., p. 38.
\end{tabular} 
[...] - nous chancelons tous dans nos enveloppes mortelles, nés pour mourir, nés pour mourir, je pourrais inscrire ces mots sur ce mur, sur tous les murs d'Amérique - Le pigeon avec ses ailes de paix, ses yeux venus de l'arche de Noé une nuit de lune; le chien avec ses griffes noires et luisantes, né pour mourir [... $]^{21}$.

Et plus loin: [...] les os magnifiques de Tristessa, elle aussi née pour mourir, sa beauté périssable, son bonheur triste, bientôt morte $[. . .]^{22}$. Ce qui ne l'empêche pas de considérer: La beauté des choses vient de ce qu'elles sont périssables 23. Mais le narrateur n'est plus seul devant l'inévitable. Une curieuse dialectique s'installe entre lui et Tristessa, elle aussi conscience de la mort. Elle connaît le caractère éphémère du genre humain: Et nous sommes rien, toi et moi 24 . Demain nous pouvons mourir 25 . Malgré cette affligeante réalité de la mort et du néant, l'amour qu'éprouve le narrateur pour Tristessa n'est-il pas une raison suffisante pour essayer de vivre?26 Mais puisque Tristessa désire la mort, la vie ne devient-elle pas insupportable pour elle? Débilitante? Incarnation de la mort, Tristessa aurait-elle renoncé à tout?

Dans la sombre nuit mexicaine où s'exhale l'odeur des tortillas, le narrateur déambule le long des rues sales, la conscience torturée et amère, laissant derrière lui le petit monde de Tristessa. Seul interlocuteur possible, ce Dieu absent:

Ô Seigneur, qu'as-tu fait d̀ tes créatures angéliques, pourquoi cette vie flétrie, cette histoire minable en lambeaux pleine de soucis et de voleurs et de mort? N'aurais-tu pas pu nous installer dans un paradis ennuyeux où tout aurait quand même été bien? Es-tu masochiste, Seigneur, es-tu un donneur d'Indiens, es-tu fait de haine?27

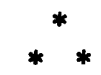

Où sont Gérard, Tristessa et tous les autres dont la présence est ici célébrée? Où sont tous ces mortels innocents devant leur piqûre de morphine? Ils subsistent dans le souffle de cette voix qui célèbre la mort, la proclame, l'éveille du sommeil où tous la tenaient cachée. Innocente activité, l'écriture serait-elle devenue cette arme ambiguë avec laquelle on lutte contre un ennemi invisible, inévitable, qui ne se présentera jamais sur les lieux du combat, mais remportera malgré tout la victoire?

Il se peut bien que l'approche de la mort, son geste souverain, son

21 Ibid., p. 46.

22 Ibid.

23 Ibid., p. 29.

24 Ibid., p. 83.

25 Ibid.

26 Ibid., p. 118.

27 Ibid., p. 90. 
ressaut dans la mémoire des hommes creusent dans l'être et le présent le vide a partir duquel et vers lequel on parle 28 .

L'approche de la mort, dont parle Michel Foucault, est peut-être la motivation première qui pousse l'individu à se bâtir, par l'écriture, des «remparts» contre la mort. Faire de sa vie une cuvre «littéraire», pour Kerouac, est le moyen de rendre «immortel» son passage sur terre. Un flot de textes aussi abondant que le sien témoigne possiblement de son désir de se protéger, par la «parole-arme», d'un ennemi qui le contraint au silence.

Comme la bête de Kafka, le langage écoute maintenant au fond de son terrier ce bruit inévitable et croissant. Et pour s'en défendre il faut bien qu'il en suive les mouvements, qu'il se constitue son fidèle ennemi [...] Il faut parler sans cesse, aussi longtemps et aussi fort que ce bruit indéfini et assourdissant [...] pour qu'en mêlant sa voix d̀ lui on parvienne sinon à le faire taire, sinon a le maittriser, du moins à moduler son inutilité en ce murmure sans terme qu'on appelle littérature 29.

Conçus à l'origine comme un véritable «combat contre l'oubli», Visions de Gérard et Tristessa s'inscrivent d'emblée dans une espèce de «combat contre la mort». Loin de la vaincre, ces œuvres réussissent à la provoquer, à lui sourire le bref instant d'une accalmie. Vue sous cet angle, l'obsession de la mort chez Kerouac participe d'une «conscientisation» aiguë du phénomène de la mort; d'une interrogation constante et anxieuse. Il ne suffit pas de dire: oui, nous mourrons! Il faut vivre et sentir la vie passer dans tout ce qui nous entoure, hommes, femmes et animaux; sentir la vie fuser de partout, et sentir, pour soimême comme pour les autres, que d'un moment à l'autre, elle ne sera plus là.

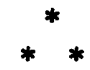

28 Michel Foucault, «Le langage à l'infini», Tel quel, $\mathrm{n}^{\circ}$ 15, automne 1963, p. 44.

29 Ibid., p. 48. 